\title{
Bacterial Membrane-Derived Vesicles Attenuate Vancomycin Activity against Methicillin-Resistant Staphylococcus aureus
}

\author{
Monika Kumaraswamy ${ }^{1,2,3, *(\mathbb{C} \text {, Kamilla Wiull }}{ }^{4,+}{ }^{+}$Bishnu Joshi ${ }^{5,+}{ }^{\circ}$, George Sakoulas ${ }^{6}$, Armin Kousha ${ }^{6}$, \\ Gustav Vaaje-Kolstad ${ }^{4}{ }^{\circ}$, Mona Johannessen ${ }^{5}$, Kristin Hegstad ${ }^{5,7}{ }^{\circledR}$, Victor Nizet ${ }^{3,6,8}$ and Fatemeh Askarian ${ }^{5,6, *}$ \\ check for \\ updates \\ 1 Infectious Diseases Section, VA San Diego Healthcare System, San Diego, CA 92161, USA \\ 2 Department of Medicine, University of California San Diego, La Jolla, CA 92093, USA \\ 3 Collaborative to Halt Antibiotic Resistant Microbes (CHARM), University of California San Diego, \\ La Jolla, CA 92093, USA; vnizet@health.ucsd.edu \\ 4 Faculty of Chemistry, Biotechnology and Food Science, Norwegian University of Life Sciences, \\ 1433 Ås, Norway; kamilla.wiull@nmbu.no (K.W.); gustav.vaaje-kolstad@nmbu.no (G.V.-K.) \\ 5 Research Group for Host-Microbe Interactions, UiT-The Arctic University of Norway, 9037 Tromsø, Norway; \\ joshi.bishnu@uit.no (B.J.); mona.johannessen@uit.no (M.J.); kristin.hegstad@uit.no (K.H.) \\ 6 Department of Pediatrics, University of California San Diego, La Jolla, CA 92093, USA; \\ gsakoulas@health.ucsd.edu (G.S.); armin.kousha@gmail.com (A.K.) \\ 7 Norwegian National Advisory Unit on Detection of Antimicrobial Resistance, \\ University Hospital of North-Norway, 9038 Tromsø, Norway \\ 8 Skaggs School of Pharmacy and Pharmaceutical Sciences, University of California San Diego, \\ La Jolla, CA 92093, USA \\ * Correspondence: mkumaraswamy@health.ucsd.edu (M.K.); faaskarian@health.ucsd.edu (F.A.) \\ + These authors contributed equally.
}

Citation: Kumaraswamy, M.; Wiull, K.; Joshi, B.; Sakoulas, G.; Kousha, A.; Vaaje-Kolstad, G.; Johannessen, M.; Hegstad, K.; Nizet, V.; Askarian, F. Bacterial Membrane-Derived Vesicles Attenuate Vancomycin Activity against Methicillin-Resistant Staphylococcus aureus. Microorganisms 2021, 9, 2055. https://doi.org/ 10.3390/microorganisms 9102055

Academic Editor: Eleonora Giovanetti

Received: 30 July 2021

Accepted: 24 September 2021

Published: 29 September 2021

Publisher's Note: MDPI stays neutral with regard to jurisdictional claims in published maps and institutional affiliations.

Copyright: (c) 2021 by the authors. Licensee MDPI, Basel, Switzerland. This article is an open access article distributed under the terms and conditions of the Creative Commons Attribution (CC BY) license (https:/ / creativecommons.org/licenses/by/ $4.0 /)$.
Abstract: Methicillin-resistant Staphylococcus aureus (MRSA) has evolved numerous antimicrobial resistance mechanisms and is identified as a serious public health threat by the World Health Organization and U.S. Centers for Disease Control and Prevention. The glycopeptide vancomycin (VAN) remains a cornerstone of therapy for severe MRSA infections despite increasing reports of therapeutic failure in hospitalized patients with bacteremia or pneumonia. Recently, the role of released bacterialderived membrane vesicles (MVs) in antibiotic resistance has garnered attention. Here we examined the effect of exogenous MRSA-derived MVs on VAN activity against MRSA in vitro, using minimum inhibitory concentration and checkerboard assays, and ex vivo, incorporating components of host innate immunity such as neutrophils and serum complement present in blood. Additionally, the proteome of MVs from VAN-exposed MRSA was characterized to determine if protein expression was altered. The presence of MVs increased the VAN MIC against MRSA to values where clinical failure is commonly observed. Furthermore, the presence of MVs increased survival of MRSA pre-treated with sub-MIC concentrations of VAN in whole blood and upon exposure to human neutrophils but not human serum. Unbiased proteomic analysis also showed an elevated expression of MV proteins associated with antibiotic resistance (e.g., marR) or proteins that are functionally linked to cell membrane/wall metabolism. Together, our findings indicate MRSA-derived MVs are capable of lowering susceptibility of the pathogen to VAN, whole-blood- and neutrophil-mediated killing, a new pharmacodynamic consideration for a drug increasingly linked to clinical treatment failures.

Keywords: methicillin-resistant Staphylococcus aureus; vancomycin; membrane vesicles

\section{Introduction}

Staphylococcus aureus (SA) are Gram-positive cocci that colonize healthy and immunocompromised individuals in both community and hospital settings. In one European study evaluating the anterior nares of 3464 patients, nearly 50\% were identified to be SA carriers [1]. A major cause of human infection-related morbidity and mortality, SA is associated with skin and soft tissue infections and invasive diseases including bacteremia, infective 
endocarditis, necrotizing pneumonia, intravascular line infection, prosthetic joint infection, osteomyelitis and toxic shock syndrome [2]. SA pathogenesis is driven by numerous virulence factors including secreted toxins (e.g., $\alpha, \beta, \gamma, \delta$, exfoliative, enterotoxin), phospholipase $C$, metalloproteases, capsular polysaccharide, protein A, fatty acid modifying enzyme and lipases, V8 protease, leukocidins, phenol soluble modulins, its golden pigment and staphylokinase [3,4].

Recently, bacterial-derived membrane vesicles (MVs) have been implicated in the pathogenesis of SA infections [5]. The spherical bi-layered MVs originate from the blebbing of bacterial outer membranes in Gram-negative bacteria or by phage endolysin-triggered cell lysis in Gram-positive bacteria [6,7]. MVs can harbor diverse cargo including biologically active toxins, $\beta$-lactamases, polysaccharides, nucleic acids and other cellular metabolites [8,9]. MVs can stimulate biofilm formation, act as immunomodulators, increase bacterial resistance to host whole-blood killing, neutrophil killing, serum-complement killing, endogenous antimicrobial peptides and pharmaceutical antibiotics, and may in part be mediated by phenol-soluble modulins [10,11]. Previous studies suggest MVs confer certain SA protection against the lipopeptide membrane-active antibiotic daptomycin in vitro and ex vivo in whole blood, and that certain antimicrobial agents (e.g., gentamicin, cefotaxime, ampicillin and imipenem) can trigger bacterial MV release, potentially yielding antimicrobial resistance [12-14]. However, the role of methicillin-resistant Staphylococcus aureus- (MRSA) derived MVs and its implications in resistance to the first line therapeutic glycopeptide antibiotic vancomycin (VAN) has yet to be explored.

MRSA appeared shortly following the introduction of methicillin in 1960 [15]. VAN was developed soon thereafter and emerged as the primary therapy for serious MRSA infections, with most isolates continuing to exhibit susceptible minimum inhibitory concentration (MIC) testing criteria as defined by the Clinical and Laboratory Standards Institute (CLSI) and the European Committee on Antimicrobial Susceptibility Testing (EUCAST), ranging between 0.5 and $2.0 \mathrm{mg} / \mathrm{L}$. VAN inhibits bacterial cell wall synthesis by binding to the d-Ala-d-Ala C peptidoglycan terminus on the outer surface of the cytoplasmic membrane, preventing further elongation and cross-linking of the peptidoglycan matrix [16]. However, despite almost uniform microbiological susceptibility, clinical treatment failures are increasingly common, particularly in high-inoculum respiratory and endovascular infections $[16,17]$. Our study explored whether exogenous MRSA-derived MVs protect the bacterium against VAN killing, or influence its clearance by neutrophils or serum complement. We also studied whether the selection pressure of sub-therapeutic concentrations of VAN altered the expression of MV proteinaceous content in MRSA using proteomics-based characterization.

\section{Materials \& Methods}

\subsection{Bacterial Strains, Media and Antibiotics}

MRSA USA 300 strain ATCC BAA-1717 (i.e., TCH1516) was used in all experiments and stored in Brain Heart Infusion (BHI) broth (Hardy Diagnostics, Santa Maria, CA, USA) with $50 \%$ glycerol at $-80{ }^{\circ} \mathrm{C}$ until the study. Mueller-Hinton broth (Spectrum Chemicals, New Brunswick, NJ, USA) supplemented with 25-50 mg/L Ca ${ }^{2+}$ (SigmaAldrich, Taufkirchen, Germany) and 10-12.5 mg/ $\mathrm{L} \mathrm{Mg}^{2+}$ (Sigma-Aldrich, Taufkirchen, Germany) (CA-MHB) served as the standard bacteriologic growth and MIC testing medium, while additional studies were performed in mammalian tissue culture medium Roswell Park Memorial Institute 1640 (ThermoFisher Scientific, MA, USA) with added 5\% BHI broth (RPMI + 5\%BHI). The antibiotics vancomycin (VAN), daptomycin (DAP), cefazolin (CFZ) and nafcillin (NAF) were purchased from Sigma-Aldrich (Taufkirchen, Germany). Note: Assays performed with DAP included a $\mathrm{Ca}^{2+}$ concentration of $50 \mathrm{mg} / \mathrm{L}$ to ensure appropriate antibiotic activity. 


\subsection{Isolation and Purification of $M V s$}

MRSA grown overnight at $37^{\circ} \mathrm{C}$ in BHI broth were diluted 1:100 $(5 / 500 \mathrm{~mL})$ in fresh BHI supplemented +/ - sub-therapeutic VAN $(0.5 \mathrm{mg} / \mathrm{L})$. Freshly inoculated cultures + / VAN were grown to stationary phase (incubated at $37^{\circ} \mathrm{C}$ for $16-17 \mathrm{~h}$ ) for MV isolation, and performed as previously described with the following modifications [5]: The culture supernatant was centrifuged at $6000 \times \mathrm{g}$ for $30-40 \mathrm{~min}$ at $4{ }^{\circ} \mathrm{C}$ and filtered through a $0.22 \mu \mathrm{m}$ vacuum filter (Merck Millipore, Darmstadt, Germany) to remove residual cellular debris. The supernatant was then ultra-centrifuged at $100,000 \times g$ at $4{ }^{\circ} \mathrm{C}$ for at least $3 \mathrm{~h}$ using either 45 or 50.2 Ti rotors (Beckman Coulter, Brea, CA, USA). The MV pellets obtained following several rounds of isolation were then pooled, washed twice with phosphate-buffered saline (Gibco PBS, Life Technologies, Carlsbad, MA, USA) following ultra-centrifugation at $100,000 \times g$ for $3 \mathrm{~h}$ at $4{ }^{\circ} \mathrm{C}$, and resuspended in fresh PBS. To ensure sterility, an aliquot of MVs was spread on BHI agar and incubated overnight at $37^{\circ} \mathrm{C}$ to verify the absence of microbial growth. Isolated MVs were then stored at $-80{ }^{\circ} \mathrm{C}$ until usage. MVs isolated in the absence of VAN were utilized in all experiments performed (checkerboards, serum killing, neutrophil killing, and whole blood killing). Only proteomic analysis was conducted using both MVs isolated in the absence and presence of sub-inhibitory VAN to help determine if antibiotic exposure altered protein expression (e.g., virulence factors and mechanisms of antimicrobial resistance).

For the proteomic analysis, pooled MVs underwent an extra fractionation step with density gradient centrifugation using OptiPrep (Sigma-Aldrich, Taufkirchen, Germany) as previously described with minor modifications [5]. Varying amounts of OptiPrep (in PBS) were sequentially added to an ultracentrifugation tube (final volume: $5 \mathrm{~mL}$ ) from bottom to top as follows: $45 \%(400 \mu \mathrm{L}), 35 \%(600 \mu \mathrm{L}), 30 \%(600 \mu \mathrm{L}), 25 \%(600 \mu \mathrm{L}), 20 \%(600 \mu \mathrm{L})$, $15 \%(500 \mu \mathrm{L})$, and $10 \%(400 \mu \mathrm{L})$. Lastly, isolated MVs were then added to the top of the tube and subjected to ultra-centrifugation at $100,000 \times \mathrm{g}$ for $3 \mathrm{~h}$ at $4{ }^{\circ} \mathrm{C}$ in slow acceleration and deceleration mode to obtain a stable layer of MV ring formation. Thereafter, $200 \mu \mathrm{L}$ aliquots (total of 25 fractions) were sequentially collected and subjected to SDS-PAGE (Life Technologies, Waltham, MA, USA) followed by Coomassie blue staining. Fractions showing the same protein profile on Coomassie stained gel were pooled (Figure S1), and submitted for transmission electron microscopy (Figure S2 and Supplementary Materials and Methods) and proteomics analysis. Concentrations of MVs containing protein were quantified using a Pierce BCA Protein Assay Kit (ThermoFisher Scientific, MA, USA) or Direct Detector ${ }^{\mathrm{TM}}$ (Merck Millipore, Darmstadt, Germany). Additionally, an Invitrogen Qubit Protein Assay Kit (MA, USA) was used for the preliminary estimation of protein concentration in the proteomic analysis per the manufacturer's instructions.

\subsection{Minimum Inhibitory Concentration and Checkerboard Assays}

Broth microdilution MIC and checkerboard assays were performed in CA-MHB in accordance with CLSI guidelines, and RPMI + 5\%BHI using antibiotics (VAN, DAP, CZN and NAF) or MVs alone or in combination [18]. The concentrations of antibiotics evaluated via MIC assays ranged from $0.5-64 \mathrm{mg} / \mathrm{L}$. The concentrations of antibiotics and MVs evaluated in combination via checkerboard assays ranged from $0-8 \mathrm{mg} / \mathrm{L}$ or $0-64 \mathrm{mg} / \mathrm{L}$ and $0-100 \mathrm{mg} / \mathrm{L}$, respectively.

\subsection{Ethical Approval}

Human whole blood (and the isolation of associated components including neutrophils and serum) was obtained from consenting healthy donors under a protocol (131002X) approved by the UC San Diego Human Subjects Institutional Review Board.

\subsection{Whole Blood Killing Assay}

MRSA viability in human whole blood was assessed as previously described with the following modifications [19]: Freshly drawn human blood anticoagulated with heparin $(160 \mu \mathrm{L})$ was mixed with $2 \times 10^{4} \mathrm{CFU}$ MRSA $(20 \mu \mathrm{L})$ grown overnight in the absence 
or presence of sub-inhibitory VAN $(0.5 \mathrm{mg} / \mathrm{L})$, or grown overnight and subsequently co-incubated with VAN $(0.5 \mathrm{mg} / \mathrm{L}), 20 \mu \mathrm{L}$ of PBS and/or $20 \mu \mathrm{L}$ of MVs (final concentration of $10 \mu \mathrm{g}$ per $100 \mu \mathrm{L}$ ) in siliconized tubes (Sigma-Aldrich, Taufkirchen, Germany). Tubes were incubated for $3 \mathrm{~h}$ at $37{ }^{\circ} \mathrm{C}$ on a rotator. Next, serial dilutions of samples were performed using sterile ice-cold MQ water + Saponin (0.3\%) (Sigma Aldrich, Taufkirchen, Germany), and were plated on Todd Hewitt Agar (THA) plates for bacterial enumeration and calculation of percentage survival vs. the initial inoculum.

\subsection{Neutrophil Killing Assay}

Neutrophil bactericidal assays were performed as previously described with the following modifications [18]: Human neutrophils were isolated from healthy donors using the PolymorphPrep system (Axis-Shield, Oslo, Norway). Freshly isolated neutrophils were resuspended to $2 \times 10^{6}$ cells $/ \mathrm{mL}$ in RPMI and used to seed a 96-well plate $\left(2 \times 10^{5}\right.$ cells/well). MRSA and/or purified MVs (final concentration of $10 \mu \mathrm{g}$ per $100 \mu \mathrm{L}$ ) were added to the applicable wells. Neutrophils were infected at a multiplicity of infection $(\mathrm{MOI})=1$ using MRSA grown overnight in the absence or presence of a sub-inhibitory concentration of VAN $(0.5 \mathrm{mg} / \mathrm{L})$. Plates were centrifuged at $500 \times g$ for $10 \mathrm{~min}$ prior to a 15 - or 30-min incubation at $37{ }^{\circ} \mathrm{C}$ with $5 \% \mathrm{CO}_{2}$. Serial dilutions of samples were performed using sterile PBS + Triton-X $100(0.02 \%)$ for bacterial enumeration and calculation of percentage survival vs. the initial inoculum.

\subsection{Serum Killing Assay}

Serum killing assays were performed using pooled serum obtained from three healthy donors and as previously described with the following modifications [20]: MRSA grown overnight with or without $0.5 \mathrm{mg} / \mathrm{L} \mathrm{VAN}\left(1.8 \times 10^{5} \mathrm{CFU} /\right.$ well $)$ were added to RPMI \pm $10 \%$ pooled human serum. Thereafter, PBS or MVs (final concentration of $10 \mu \mathrm{g}$ per $100 \mu \mathrm{L}$ ) were added to samples. Assays were performed with a final volume of $300 \mu \mathrm{L}$ using siliconized tubes rotated in a $37^{\circ} \mathrm{C}$ incubator for $1 \mathrm{~h}$ before completing serial dilutions with sterile PBS followed by plating on THA for CFU enumeration. The survival index was defined as CFU enumerated at the end of the assay divided by CFU present at the $0 \mathrm{~h}$ time point.

\subsection{Growth Curve}

MRSA inoculated in $5 \mathrm{~mL}$ of $\mathrm{BHI}$ or CA-MHB were grown overnight to stationary phase $(14-16 \mathrm{~h})$ at $37^{\circ} \mathrm{C}$ in a shaking incubator. The next day, the bacteria were washed twice with PBS and resuspended in fresh BHI or CA-MHB to $1 \times 10^{6} \mathrm{CFU} / \mathrm{mL}+/-$ VAN $(0.5 \mathrm{mg} / \mathrm{L})$ and used to seed a 96 -well flat bottom plate $\left(1 \times 10^{5} \mathrm{CFU} /\right.$ well $)$. Plates were subsequently placed in a Bioscreen C MBR reader (Oy Growth Curves Ab Ltd., Turku, Finland) maintained at $37^{\circ} \mathrm{C}$ with re-growth assessed by $\mathrm{OD}_{600}$ every $6 \mathrm{~h}$.

\subsection{Proteomic and Bioinformatic Analysis of MVs Containing Protein}

In-solution digestion and liquid chromatography mass spectrometry (MS) were performed by UiT-The Arctic University of Norway's Proteomic Core Facility using MVs isolated from MRSA in the absence and presence of VAN as described earlier [21,22]. The protein pellet $(20 \mu \mathrm{g})$ was resuspended in $8 \mathrm{M}$ urea, reduced with $20 \mathrm{mM}$ dithiothreitol (DTT), and alkylated by treatment with $40 \mathrm{mM}$ iodoacetamide prior to trypsinization (1:20) (Promega, Madison, WI, USA). Peptide purification and desalting was performed using OMIX C18 tips (Varian, Crawley, CA, USA). The purified peptide was dissolved in $0.1 \%$ formic acid and injected on an Easy-nLC autosampler (Thermo Fisher Scientific, Waltham, MA, USA) containing an EASY-Spray column (C18, $2 \mu \mathrm{m}, 100 \AA$, $50 \mu \mathrm{m}, 50 \mathrm{~cm})$. Nano liquid chromatography (LC) was run at a flow rate of $250 \mathrm{~nL} / \mathrm{min}$ containing $2-100 \%$ acetonitrile gradient in $0.1 \%$ formic acid over $50 \mathrm{~min}$. Separated peptides were analyzed using a Q-Exactive mass spectrometer (Thermo Fisher Scientific, Waltham, MA, USA). Data were collected in data-dependent mode using a Top10 method. Raw data were searched 
against SA M1516 (from NCBI) using the Sequest algorithm in Proteome Discoverer version 2.1 [23]. Peptide mass tolerances used in the search were $10 \mathrm{ppm}$, and fragment mass tolerance was $0.02 \mathrm{Da}$. Peptide ions were filtered using a false discovery rate (FDR) set to $5 \%$ for protein identifications. Networking and enrichment analyses were performed using STRING database [24]. For the appropriate input, GI numbers were converted to the corresponding UniProtKB ID; in total, 521 of $530 \mathrm{MV}$-associated proteins were mapped into UniProtKB ID. Virulence factors were selected either from the list provided in the following link: http:/ / www.mgc.ac.cn/cgi-bin/VFs/compvfs.cgi?Genus=Staphylococcus (23 September 2021) or through a literature review.

\subsection{Statistical Analysis}

Data were represented as the mean \pm SEM of three experiments unless otherwise specified. Two-way analyses of variance were used where appropriate. $p$-values $<0.05$ were regarded to be statistically significant. All statistical analyses were performed using GraphPad Prism 8.0 (GraphPad Software).

\section{Results}

\subsection{Exogenous MVs Promote MRSA Survival in the Presence of VAN}

MIC and checkerboard assays were performed using cell-membrane/wall-targeting antibiotics DAP, NAF, CFZ and VAN alone or in combination with exogenous MRSAderived MVs and the clinical strain MRSA TCH1516. Studies were performed in the bacteriologic media CA-MHB, or in the supplemented mammalian tissue culture media RPMI + 5\%BHI (Table 1). The DAP (2 vs. $0.5 \mathrm{mg} / \mathrm{L}), \mathrm{NAF}$ (64 vs. $4 \mathrm{mg} / \mathrm{L}$ ), and CFZ (64 vs. $4 \mathrm{mg} / \mathrm{L}$ ) MICs were notably lower using RPMI + 5\%BHI compared to CA-MHB but unchanged for VAN (1 vs. $1 \mathrm{mg} / \mathrm{L}$ ). Exposure to exogenous MRSA-derived MVs (25-100 or 50-100 mg/L) together with VAN, an antibiotic commonly deployed in the management of SA infections, increased the MIC of VAN from a susceptible MIC of $1 \mathrm{mg} / \mathrm{L}$ to a more resistant MIC of 2 (borderline susceptible) and $4 \mathrm{mg} / \mathrm{L}$ (resistant) in CA-MHB and RPMI + 5\%BHI, respectively, and based on clinical breakpoints determined by CLSI and EUCAST (Figure 1A). In contrast, the concomitant presence of MVs did not increase the MICs of NAF, CFZ or DAP in either medium (Figure 1B and Table 1).

Table 1. Antimicrobial susceptibility of methicillin-resistant Staphylococcus aureus (MRSA) to cell-wall- or cell-membranetargeting antibiotics in the absence and presence of exogenous bacterial-derived membrane vesicles (MVs) determined using minimum inhibitory concentration (MIC) and checkerboard assays.

\begin{tabular}{ccccccccc}
\hline \multirow{2}{*}{ MRSA (TCH 1516) } & \multicolumn{4}{c}{- MVs $(\mathbf{0 ~ m g / L ) ~}$} & \multicolumn{3}{c}{+ MVs (1.56-100 mg/L) } \\
\cline { 2 - 9 } & VAN & DAP & CFZ & NAF & VAN $^{\text {a }}$ & DAP & CFZ & NAF \\
\hline CA-MHB & 1 & 2 & $\geq 64$ & $\geq 64$ & 2 & 2 & $\geq 64$ & $\geq 64$ \\
RPMI + 5\%BHI & 1 & 0.5 & 4 & 4 & 4 & 0.5 & 4 & 4 \\
\hline
\end{tabular}

Data are represented as $\mathrm{mg} / \mathrm{L}$. ${ }^{a}$ VAN MIC increased from 1 to $2 \mathrm{mg} / \mathrm{L}$ and 1 to $4 \mathrm{mg} / \mathrm{L}$ in the presence of MV concentrations ranging from $25-100 \mathrm{mg} / \mathrm{L}$ and 50-100 mg/L in CA-MHB and RPMI + 5\%BHI, respectively. MRSA: Methicillin-Resistant Staphylococcus aureus; MVs: Membrane Vesicles; MIC: Minimum Inhibitory Concentration; CA-MHB: Cation-adjusted Mueller-Hinton Broth; RPMI + 5\%BHI: Roswell Park Memorial Institute $1640+5 \%$ Brain Heart Infusion; VAN: Vancomycin; DAP: Daptomycin; CFZ: Cefazolin; NAF: Nafcillin.

\subsection{MVs, VAN and Innate Immune Mediated Killing of MRSA}

MV enhancement of MRSA survival in the presence of VAN was further evaluated in the context of host innate defenses by ex vivo assays incorporating whole blood, neutrophils or serum complement. Direct co-incubation of MRSA with $0.5 \mathrm{mg} / \mathrm{L}$ VAN and $20 \mu \mathrm{g}$ of MVs increased bacterial survival in freshly isolated human whole blood that harbors multiple components of innate immunity including leukocytes, platelets and serum complement (Figure 2A). Furthermore, the presence of MVs also promoted resistance of MRSA pretreated overnight with sub-MIC concentrations of VAN $(0.5 \mathrm{mg} / \mathrm{L})$ to killing by whole blood and purified human neutrophils but not by serum complement (Figure 2A-C). Our 
ex vivo studies suggest increased MRSA survival in the presence of MV may be partially mediated by encumbrances to neutrophil killing.

A
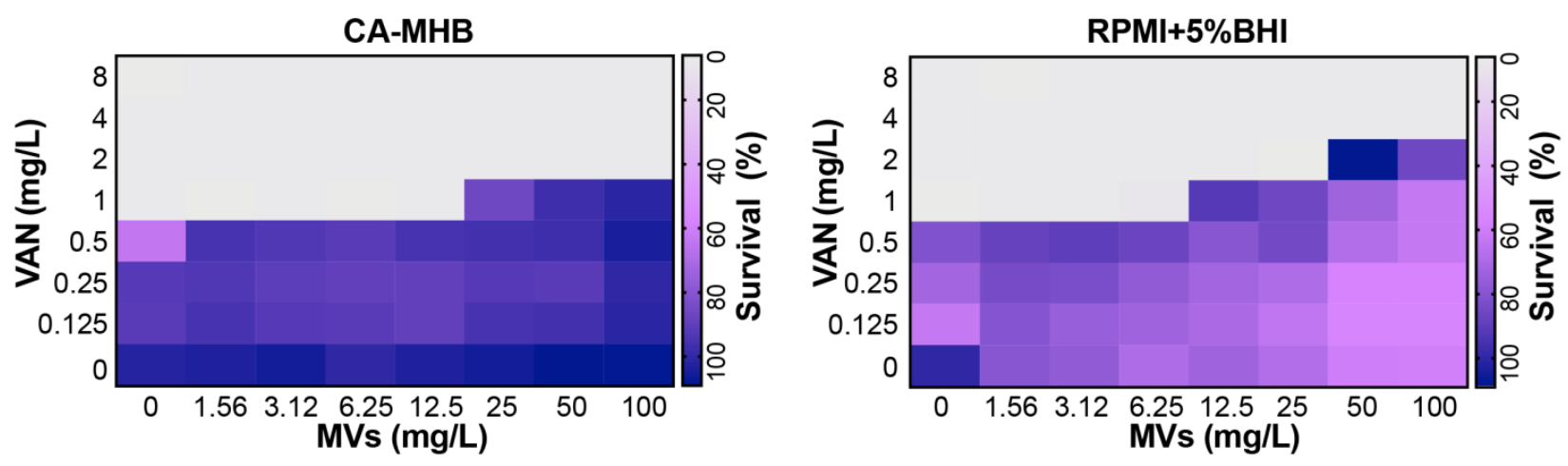

в
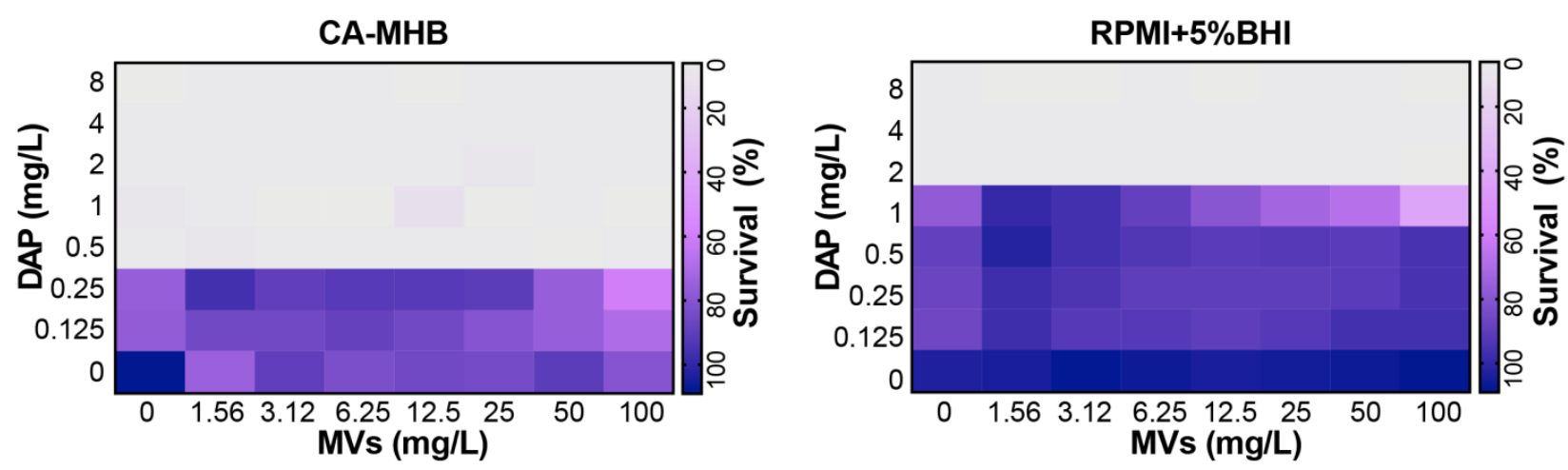

Figure 1. MVs potentiate MRSA survival in the presence of VAN. Antimicrobial susceptibility of MRSA to (A) VAN or (B) DAP in combination with MVs was assessed by checkerboard broth microdilution assays performed in CA-MHB or RPMI + $5 \%$ BHI. Bacterial growth quantified by $\mathrm{OD}_{600}$ and compared to the growth of untreated control wells was reflected as a heat map of percentage bacterial survival. Data are representative of at least two biologic replicates. CA-MHB: Cation-adjusted Mueller-Hinton Broth; RPMI + 5\%BHI: Roswell Park Memorial Institute 1640 + 5\% Brain Heart Infusion; VAN: Vancomycin; DAP: Daptomycin; MVs: Membrane Vesicles.

A

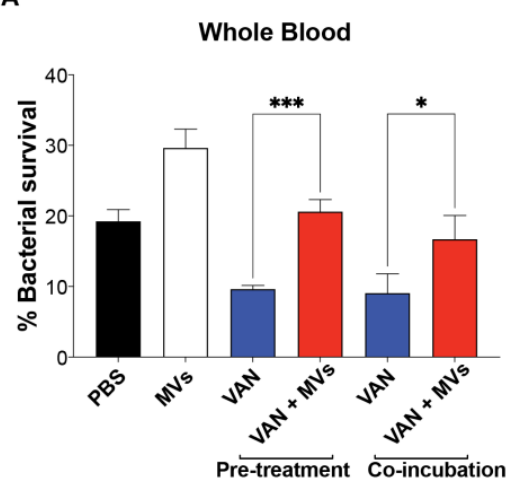

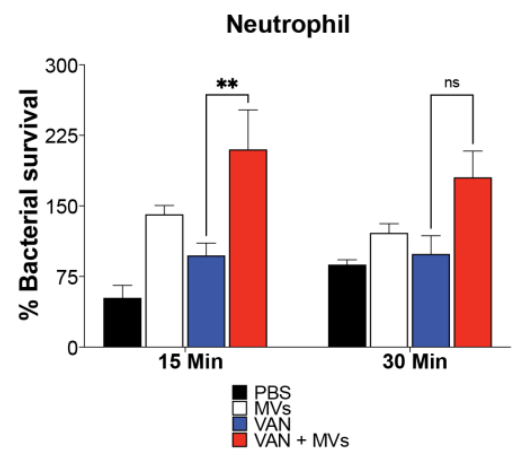

C

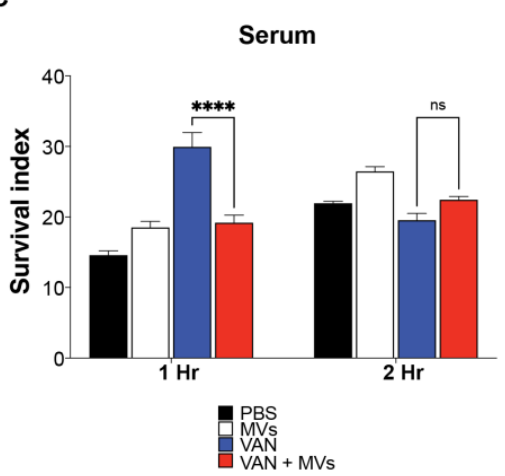

Figure 2. Ex vivo analysis of MRSA, VAN, MVs and components of host innate immunity. MRSA grown overnight or co-incubated with $0.5 \mathrm{mg} / \mathrm{L}$ of VAN are more resistant to killing by $(\mathbf{A})$ human whole blood $(3 \mathrm{~h})$ and $(\mathbf{B})$ isolated neutrophils (15 and $30 \mathrm{~min})$ in the presence of MVs $(20 \mu \mathrm{g})$. However, exogenous MVs did not significantly increase the killing of MRSA pre-treated overnight with $0.5 \mathrm{mg} / \mathrm{L}$ of VAN to $(\mathbf{C})$ human serum complement $(1 \mathrm{and} 2 \mathrm{~h})$. Data are representative of the mean \pm SEM from a combination of three experiments performed in triplicate. ${ }^{*} p<0.05,{ }^{* *} p<0.01,{ }^{* * *} p<0.001$, ${ }^{* * * *} p<0.0001$, or no statistical significance (ns) in VAN treated samples by two-way ANOVA. PBS: Phosphate-Buffered Saline; MVs: Membrane Vesicles; VAN: Vancomycin. 


\subsection{VAN Exposure Influences MRSA MV Proteome Content}

The MS/MS spectra of MV proteins isolated from MRSA TCH1516 untreated or pre-treated overnight with a sub-bacteriostatic concentration of $(0.5 \mathrm{mg} / \mathrm{L})$ VAN were compared vs. the well-annotated genome of SA M1516. Pre-treatment with VAN did not impede the growth of MRSA in BHI or CA-MHB (Figure 3A). A total of 509 and 545 proteins were identified from MVs isolated from untreated or VAN pre-treated MRSA grown in BHI (Figure 3B and Supplementary Dataset Supplementary 1), respectively. Ultimately, 504 proteins were assigned to a common proteome, and notably, 41 unique proteins were associated with VAN exposure (Table 2). Some of the identified unique proteins are associated with VAN pre-treatment including $\mathrm{N}$-acetylglucosamine-1-phosphate uridyltransferase $(g l m U)$, acetyl-CoA biotin carboxylase $(a c c C)$, glycerol kinase $(g l p K)$, and proteases ( $h$ trA and SAUSA300_0816) previously found to be upregulated in response to other cell-walldamaging antibiotics (oxacillin, cycloserine, bacitracin, etc.) and are functionally linked to cell membrane/wall metabolism or maintenance of important periplasmic and membrane proteins (Figure 3C and Supplementary Dataset 1) [25,26].

Table 2. Unique proteins associated with MVs isolated from MRSA, grown in the presence of sub-MIC VAN (0.5 mg/L).

\begin{tabular}{|c|c|}
\hline Gene Symbol/ORF & Description \\
\hline$d u t$ & dUTP diphosphatase \\
\hline purE & N5-carboxyaminoimidazole ribonucleotide mutase \\
\hline vals & Valine-tRNA ligase \\
\hline rocF & Arginase \\
\hline SAUSA300_2144 & Uncharacterized protein \\
\hline$g \operatorname{lm} U$ & Bifunctional protein GlmU \\
\hline HMPREF0776_2553 & Dehydrogenase E1 component \\
\hline alas & Alanine-tRNA ligase \\
\hline HMPREF0776_0959 & Acetyl-CoA C-acetyltransferase \\
\hline SAUSA300_2328 & Uncharacterized protein \\
\hline$d m p I$ & Tautomerase \\
\hline mtlD & Mannitol-1-phosphate 5-dehydrogenase \\
\hline SAUSA300_0003 & Uncharacterized protein \\
\hline SAUSA300_1690 & Putative thioredoxin \\
\hline HMPREF0776_2533 & Alpha-amylase \\
\hline SAUSA300_0289 & Uncharacterized protein \\
\hline lysS & Lysine-tRNA ligase \\
\hline pyrG & CTP synthase \\
\hline SAUSA300_0706 & Putative osmoprotectant $\mathrm{ABC}$ transporter, ATP-binding protein \\
\hline SA0224 & 3-hydroxyacyl-CoA dehydrogenase, NAD binding domain protein \\
\hline rec $A$ & Protein RecA \\
\hline HMPREF0776_0345 & Accessory regulator family \\
\hline SAUSA300_2132 & UPF0457 protein SAUSA300_2132 \\
\hline $\operatorname{accC}$ & Acetyl-CoA carboxylase, biotin carboxylase \\
\hline HMPREF0776_2830 & Excalibur domain protein \\
\hline SAUSA300_0460 & Uncharacterized protein \\
\hline hflB ftsH & ATP-dependent zinc metalloprotease FtsH \\
\hline SAUSA300_2289 & Uncharacterized protein \\
\hline$i s d B$ & Iron-regulated surface determinant protein B \\
\hline srrA & Staphylococcal respiratory response protein, SrrA \\
\hline $\operatorname{cod} Y$ & GTP-sensing transcriptional pleiotropic repressor CodY \\
\hline SAUSA300_0816 & UPF0337 protein SAUSA300_0816 \\
\hline rps $D$ & $30 S$ ribosomal protein $S 4$ \\
\hline HMPREF0776_2441 & Peptidase, S41 family \\
\hline $\operatorname{rps} R$ & 30 S ribosomal protein $\mathrm{S} 18$ \\
\hline HMPREF0776_1767 & HD domain protein \\
\hline SAUSA300_1674 & Putative serine protease HtrA \\
\hline HMPREF0776_0647 & Uncharacterized protein \\
\hline EP54_02570 & Lipoprotein \\
\hline$g l p K^{-}$ & Glycerol kinase \\
\hline HMPREF0776_2430 & Glyoxalase family protein \\
\hline
\end{tabular}




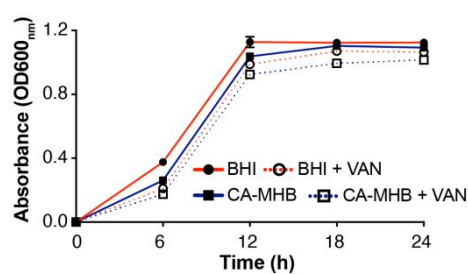

C
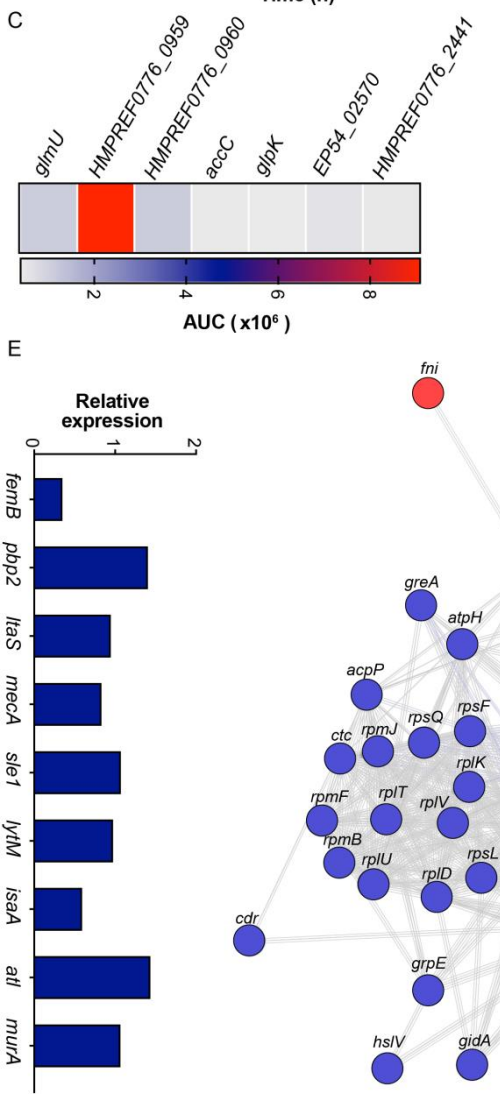
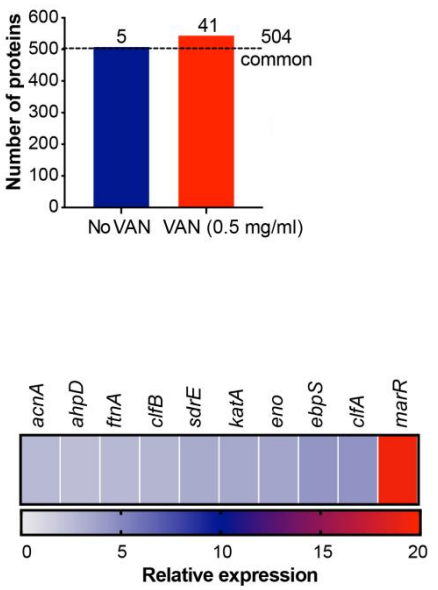

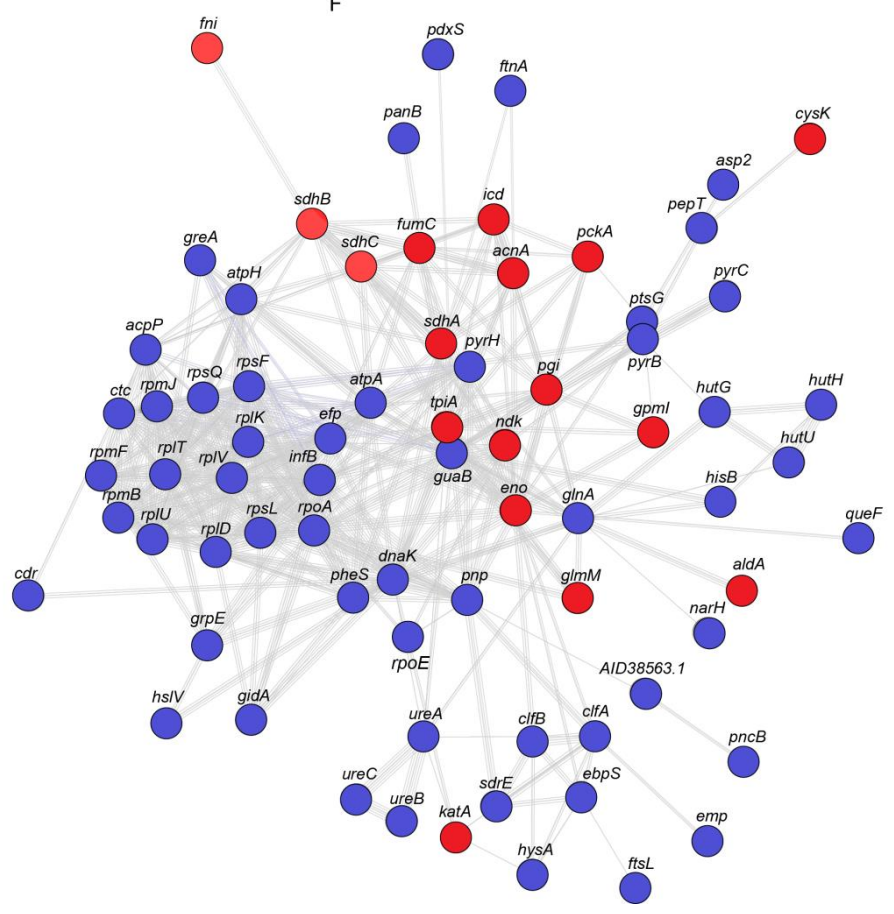

Figure 3. Proteomic profile of MV peptides derived from VAN pre-treated MRSA. (A) Growth of MRSA in BHI or CA-MHB + / - VAN (0.5 mg/L) at $24 \mathrm{~h}$ was not impeded by the presence of sub-MIC VAN. (B) Number of proteins identified from MVs isolated from untreated or VAN pre-treated MRSA. Heat maps illustrating unique MV proteins associated with (C) cell wall or cell membrane metabolism and (D) virulence from MRSA pre-treated with VAN are represented as the area under the curve (AUC) or relative expression ( $>2$-fold expression relative to proteins identified from untreated MRSA-derived MVs), respectively. (E) Expression of proteins involved in cell wall biosynthesis (e.g., peptidoglycan and lipoteichoic acid) from MV proteins derived from VAN pre-treated MRSA relative to untreated MRSA. (F) Functional STRING and KEGG analyses of proteins expressed under selective pressure from sub-MIC VAN demonstrated a highly interconnected network of proteins associated with general metabolic processes (gray), virulence (blue) and antibiotic resistance (red). Singletons or chains with no interaction within the main network have been deleted. Gene nomenclatures are depicted in Supplementary Dataset 1 and 2. MVs: Membrane Vesicles; BHI: Brain Heart Infusion; CA-MHB: Cation-adjusted Mueller-Hinton Broth; VAN: Vancomycin; HMPREF0776_0959: AcetylCoA C-acetyltransferase; HMPREF0776_0960: 3-hydroxyacyl-CoA Dehydrogenase; EP54_02570: Lipoprotein; HMPREF0776_244: Peptidase (S41 Family).

The abundance of several virulence factors with established roles in SA pathogenesis (e.g., clumping factor A $(c l f A)$, clumping factor B $(c l f B)$, serine aspartate repeat containing 
protein $\mathrm{E}(s d r E)$, elastin binding protein $(e b p S)$ ), evasion of host oxidative stress (e.g., alkyl hydroperoxide reductase $(a h p D)$, bacterial non-heme ferritin $(f t n A)$, catalase (kat $A)$ ) and bacterial detoxification to diverse antibiotics including norfloxacin and ampicillin (by the multiple antibiotic resistance regulator (marR) family of transcription factors) were markedly increased ( $>2$ - to 19-fold change) in the MVs isolated from MRSA pretreated with VAN relative to untreated MRSA (Figure 3D and Supplementary Dataset 2). Furthermore, penicillin binding protein 2 (PBP2), whose expression is essential for VAN glycopeptide resistance and cell wall biosynthesis, was also increased by 1.4-fold in MVs derived from MRSA exposed to VAN (Figure 3E) [27-29]. A KEGG network analysis of proteins highly expressed in MVs from VAN pre-treated MRSA were highly interconnected and predominantly associated with metabolic processes, virulence, and antibiotic resistance (Figure 3F). Our data indicate that the elevated relative expression of proteins captured in the released membrane vesicles of VAN pre-treated MRSA reflects a bacterial proteomic response that is modulating antibiotic and innate immune susceptibility.

\section{Discussion}

VAN remains a first-line antibiotic in the treatment of severe MRSA infection based on high rates of susceptibility identified by MIC testing and its low cost [30]. However, increased mortality and treatment failures have been seen in patients with MRSA bacteremia and hospital-acquired MRSA infections treated with VAN irrespective of the corresponding MIC [17,31,32]. Our study suggests MV and MV-associated proteins produced in response to antibiotic exposure and environmental stressors may influence VAN susceptibility by functioning as a cell wall/membrane decoy to sequester the antibiotic, and may also have ramifications on the pathogen's susceptibility to neutrophil and whole-blood killing.

MIC and checkerboard testing revealed the presence of MVs in standard bacteriologic (CA-MHB) and supplemented mammalian tissue culture (RPMI $+5 \% \mathrm{BHI}$ ) mediums raised the MIC of VAN from $1 \mathrm{mg} / \mathrm{L}$ to $2 \mathrm{mg} / \mathrm{L}$ and $2 \mathrm{mg} / \mathrm{L}$ to $4 \mathrm{mg} / \mathrm{L}$, respectively (Figure $1 \mathrm{~A}$ ). The current clinical MIC breakpoint of VAN for MRSA is $2 \mathrm{mg} / \mathrm{L}$ according to EUCAST and CLSI guidelines, so the magnitude of observed MIC elevation approached or exceeded the clinical breakpoint where clinical failure is often observed and supplemental or alternative antibiotic regimens are typically pursued [31,33,34].

Conversely, the presence of MVs did not influence the MIC of DAP, an alternative agent for MRSA infection, in either CA-MHB or RPMI $+5 \%$ BHI (Figure 1B). Loss of the accessory gene regulator (agr) quorum sensing system, a regulator of virulence gene expression, enhances MRSA resistance to DAP by shedding membrane phospholipids [13]. However, the virulent MRSA TCH1516 used in our investigation harbored an intact agr locus [35]. Although MRSA harboring agr release membrane phospholipids in response to DAP, they also secrete phenol-soluble modulins, small cytolytic toxins that counteract DAP inactivation. Pader et al. demonstrated that SA phospholipid shedding was inhibited by oxacillin (OXA), a $\beta$-lactam antibiotic used in combination with DAP as salvage therapy in recalcitrant MDR staphylococcal infections, boosting bacterial killing in experimental in vivo models [13].

The relevance of our findings with VAN were extended to interactions with innate immunity. Ex vivo assays using human whole blood revealed MVs enhanced survival of MRSA co-incubated or pre-treated overnight with VAN compared to that of MRSA in the absence of antibiotics (Figure 2A). Additionally, the presence of MVs promoted resistance of MRSA pre-treated with VAN to neutrophil, but not serum killing (Figure 2B,C). Proteomic analysis of MVs identified catalase $(k a t A)$, alkyl hydroperoxide reductase ( $\operatorname{ha} p \mathrm{C}, \operatorname{ahpF})$, leukocidins (lukE, lukS) and $\alpha$-hemolysin (hla), enzymes known to reduce oxidative burst triggered by phagocytic cells such as neutrophils, and potent toxins known to target and lyse host immune cells [36].

Furthermore, MV proteomic analysis of VAN-treated MRSA showed increased expression of virulence factors predominantly associated with adhesion and colonization of the nares, skin, elastin-rich tissues and foreign bodies, bacterial clumping and fibrin 
clot formation including clumping factors $\mathrm{A}$ and $\mathrm{B}$, serine aspartate repeat containing protein $\mathrm{E}$, and elastin-binding protein. Indeed, the interesting epidemiological association of MRSA colonization being associated with prior glycopeptide exposure may be attributed at least in part by these observations [37]. Higher levels ( $>19$-fold) of the marR family of transcription factors, proteins known to facilitate resistance to $\beta$-lactams, quinolones or whose upregulation have been implicated in VAN resistance, were also detected [27-29,38].

In conclusion, these findings highlighting MV shedding by SA may represent an adaptive mechanism against VAN exposure and may increase the concentration of VAN required to achieve bacterial clearance. Our investigation represents a first step in exposing the potential involvement of MVs in VAN therapeutic failure observed in severe MRSA infections, and may be another pharmacodynamic consideration in the evaluation of VAN vs. alternative mono and dual therapies (such as DAP, or DAP + OXA) which are potentially less susceptible to being thwarted by MV release. Future studies including multiple clinical MRSA strains obtained from infections involving VAN therapeutic failure, quantification of MV production in high-burden infections, visualization of antibiotic entrapment by MVs, and in vivo studies must be performed to address the limitations of our preliminary proof-of-principle studies and assess the broader applicability of our findings.

Supplementary Materials: The following are available online at https://www.mdpi.com/article/10 $.3390 /$ microorganisms9102055/s1. Supplementary Materials for this article include Supplementary Materials and Methods (Transmission Electron Microscopy Analysis), Supplementary Figures S1-S2, Dataset legend, Supplementary References, and Supplementary Datasets (1-2). Figure S1: Coomassie blue stained protein gel of pooled MRSA-derived MVs fractions. Figure S2: TEM of MVs isolated from MRSA (TCH1516) after OptiPrep. Dataset 1: List of identified MRSA-derived MV proteins obtained from bacteria grown in BHI in the absence or presence of sub-MIC VAN $(0.5 \mathrm{mg} / \mathrm{L})$. The results were obtained from pooled MVs purified from multiple isolations. Protein abundance is represented as the area under the curve (AUC). Dataset 2: List of identified MRSA-derived MV proteins with increased expression ( $>2$ fold) in the presence of sub-MIC VAN relative to no VAN.

Author Contributions: Conceptualization, M.K., G.S., V.N. and F.A.; methodology, M.K., B.J. and F.A.; formal analysis, M.K., K.W. and F.A.; investigation, M.K., B.J., A.K. and F.A.; writing-original draft, M.K. and F.A.; writing—review \& editing, M.K., K.W., B.J., G.S., A.K., G.V.-K., M.J., K.H., V.N. and F.A.; supervision, M.K., V.N. and F.A.; funding acquisition, M.K., G.S. and V.N.; resources, M.J., K.H., G.S. and V.N.; All authors have read and agreed to the published version of the manuscript.

Funding: This work was supported by the National Institute of Health grants U54-HD090259 (to G.S. and V.N.), 1U01AI124316-01 (to M.K., G.S. and V.N.), 1KL2TR001444 (to M.K.), and 1R01AI14531001A1 (to M.K. and V.N.).

Institutional Review Board Statement: The study was conducted according to the guidelines of the Declaration of Helsinki, and approved by the UC San Diego Human Subjects Institutional Review Board (131002X).

Informed Consent Statement: Informed consent was obtained from all subjects involved in the study.

Data Availability Statement: Proteomic data have been uploaded to the Proteomics Identification Database (PRIDE) (PXD024232).

Acknowledgments: We thank Jack Brunn from UiT-The Arctic University of Norway's Proteomic Core Facility for his assistance with proteomic processing and analysis.

Conflicts of Interest: The authors declare that there is no conflict of interest.

\section{References}

1. Mertz, D.; Frei, R.; Periat, N.; Zimmerli, M.; Battegay, M.; Fluckiger, U.; Widmer, A.F. Exclusive Staphylococcus aureus throat carriage: At-risk populations. Arch. Intern. Med. 2009, 169, 172-178. [CrossRef]

2. Brown, A.F.; Leech, J.M.; Rogers, T.R.; McLoughlin, R.M. Staphylococcus aureus Colonization: Modulation of Host Immune Response and Impact on Human Vaccine Design. Front. Immunol. 2014, 4, 507. [CrossRef]

3. Tam, K.; Torres, V.J. Staphylococcus aureus Secreted Toxins and Extracellular Enzymes. Microbiol. Spectr. 2019, 7. [CrossRef]

4. Peschel, A.; Otto, M. Phenol-soluble modulins and staphylococcal infection. Nat. Rev. Microbiol. 2013, 11, 667-673. [CrossRef] 
5. Askarian, F.; Lapek, J.D., Jr.; Dongre, M.; Tsai, C.M.; Kumaraswamy, M.; Kousha, A.; Valderrama, J.A.; Ludviksen, J.A.; Cavanagh, J.P.; Uchiyama, S.; et al. Staphylococcus aureus Membrane-Derived Vesicles Promote Bacterial Virulence and Confer Protective Immunity in Murine Infection Models. Front. Microbiol. 2018, 9, 262. [CrossRef]

6. Toyofuku, M.; Carcamo-Oyarce, G.; Yamamoto, T.; Eisenstein, F.; Hsiao, C.C.; Kurosawa, M.; Gademann, K.; Pilhofer, M.; Nomura, N.; Eberl, L. Prophage-triggered membrane vesicle formation through peptidoglycan damage in Bacillus subtilis. Nat. Commun. 2017, 8, 481. [CrossRef]

7. Toyofuku, M.; Nomura, N.; Eberl, L. Types and origins of bacterial membrane vesicles. Nat. Rev. Microbiol. 2019, 17, 13-24. [CrossRef] [PubMed]

8. Brown, L.; Wolf, J.M.; Prados-Rosales, R.; Casadevall, A. Through the wall: Extracellular vesicles in Gram-positive bacteria, mycobacteria and fungi. Nat. Rev. Microbiol. 2015, 13, 620-630. [CrossRef] [PubMed]

9. Deatherage, B.L.; Cookson, B.T. Membrane vesicle release in bacteria, eukaryotes, and archaea: A conserved yet underappreciated aspect of microbial life. Infect. Immun. 2012, 80, 1948-1957. [CrossRef] [PubMed]

10. Yu, Y.J.; Wang, X.H.; Fan, G.C. Versatile effects of bacterium-released membrane vesicles on mammalian cells and infectious/inflammatory diseases. Acta Pharmacol. Sin. 2018, 39, 514-533. [CrossRef] [PubMed]

11. Caruana, J.C.; Walper, S.A. Bacterial Membrane Vesicles as Mediators of Microbe-Microbe and Microbe-Host Community Interactions. Front. Microbiol. 2020, 11, 432. [CrossRef]

12. Andreoni, F.; Toyofuku, M.; Menzi, C.; Kalawong, R.; Mairpady Shambat, S.; Francois, P.; Zinkernagel, A.S.; Eberl, L. Antibiotics Stimulate Formation of Vesicles in Staphylococcus aureus in both Phage-Dependent and -Independent Fashions and via Different Routes. Antimicrob. Agents Chemother. 2019, 63, e01439-18. [CrossRef]

13. Pader, V.; Hakim, S.; Painter, K.L.; Wigneshweraraj, S.; Clarke, T.B.; Edwards, A.M. Staphylococcus aureus inactivates daptomycin by releasing membrane phospholipids. Nat. Microbiol. 2016, 2, 16194. [CrossRef] [PubMed]

14. Kim, S.W.; Seo, J.S.; Park, S.B.; Lee, A.R.; Lee, J.S.; Jung, J.W.; Chun, J.H.; Lazarte, J.M.S.; Kim, J.; Kim, J.H.; et al. Significant increase in the secretion of extracellular vesicles and antibiotics resistance from methicillin-resistant Staphylococcus aureus induced by ampicillin stress. Sci. Rep. 2020, 10, 21066. [CrossRef] [PubMed]

15. CDC. Antibiotic Resistance Threats in the United States; U.S. Department of Health and Human Services, CDC: Atlanta, GA, USA, 2019.

16. Barna, J.C.; Williams, D.H. The structure and mode of action of glycopeptide antibiotics of the vancomycin group. Annu. Rev. Microbiol. 1984, 38, 339-357. [CrossRef]

17. Walraven, C.J.; North, M.S.; Marr-Lyon, L.; Deming, P.; Sakoulas, G.; Mercier, R.C. Site of infection rather than vancomycin MIC predicts vancomycin treatment failure in methicillin-resistant Staphylococcus aureus bacteraemia. J. Antimicrob. Chemother. 2011, 66, 2386-2392. [CrossRef] [PubMed]

18. Kumaraswamy, M.; Lin, L.; Olson, J.; Sun, C.F.; Nonejuie, P.; Corriden, R.; Dohrmann, S.; Ali, S.R.; Amaro, D.; Rohde, M.; et al. Standard susceptibility testing overlooks potent azithromycin activity and cationic peptide synergy against MDR Stenotrophomonas maltophilia. J. Antimicrob. Chemother. 2016, 71, 1264-1269. [CrossRef]

19. Askarian, F.; Uchiyama, S.; Valderrama, J.A.; Ajayi, C.; Sollid, J.U.; van Sorge, N.M.; Nizet, V.; van Strijp, J.A.; Johannessen, M. Serine-aspartate-repeat protein D Increases Staphylococcus aureus Virulence and Survival in Blood. Infect. Immun. 2017, 85, e00559-16. [CrossRef]

20. Kumaraswamy, M.; Do, C.; Sakoulas, G.; Nonejuie, P.; Tseng, G.W.; King, H.; Fierer, J.; Pogliano, J.; Nizet, V. Listeria monocytogenes endocarditis: Case report, review of the literature, and laboratory evaluation of potential novel antibiotic synergies. Int. J. Antimicrob. Agents 2018, 51, 468-478. [CrossRef] [PubMed]

21. Wagner, T.; Joshi, B.; Janice, J.; Askarian, F.; Škalko-Basnet, N.; Hagestad, O.; Mekhlif, A.; Wai, S.; Hegstad, K.; Johannessen, M. Enterococcus faecium produces membrane vesicles containing virulence factors and antimicrobial resistance related proteins. $J$. Proteom. 2018, 187, 28-38. [CrossRef]

22. Cavanagh, J.P.; Pain, M.; Askarian, F.; Bruun, J.-A.; Urbarova, I.; Wai, S.N.; Schmidt, F.; Johannessen, M. Comparative exoproteome profiling of an invasive and a commensal Staphylococcus haemolyticus isolate. J. Proteom. 2018, 197, 106-114. [CrossRef] [PubMed]

23. Eng, J.K.; McCormack, A.L.; Yates, J.R. An approach to correlate tandem mass spectral data of peptides with amino acid sequences in a protein database. J. Am. Soc. Mass Spectrom. 1994, 5, 976-989. [CrossRef]

24. Szklarczyk, D.; Gable, A.L.; Lyon, D.; Junge, A.; Wyder, S.; Huerta-Cepas, J.; Simonovic, M.; Doncheva, N.T.; Morris, J.H.; Bork, P.; et al. String V11: Protein-Protein Association Networks with Increased Coverage, Supporting Functional Discovery in Genome-Wide Experimental Datasets. Nucleic Acids Res. 2019, 47, D607-D613. [CrossRef] [PubMed]

25. Bibek, G.C.; Sahukhal, G.S.; Elasri, M.O. Role of the msaABCR Operon in Cell Wall Biosynthesis, Autolysis, Integrity, and Antibiotic Resistance in Staphylococcus aureus. Antimicrob. Agents Chemother. 2019, 63. [CrossRef]

26. Utaida, S.; Dunman, P.M.; Macapagal, D.; Murphy, E.; Projan, S.J.; Singh, V.K.; Jayaswal, R.K.; Wilkinson, B.J. Genome-wide transcriptional profiling of the response of Staphylococcus aureus to cell-wall-active antibiotics reveals a cell-wall-stress stimulon. Microbiology 2003, 149, 2719-2732. [CrossRef]

27. Labischinski, H.; Ehlert, K.; Berger-Bachi, B. The targeting of factors necessary for expression of methicillin resistance in staphylococci. J. Antimicrob. Chemother. 1998, 41, 581-584. [CrossRef] 
28. Severin, A.; Wu, S.W.; Tabei, K.; Tomasz, A. Penicillin-binding protein 2 is essential for expression of high-level vancomycin resistance and cell wall synthesis in vancomycin-resistant Staphylococcus aureus carrying the enterococcal vanA gene complex. Antimicrob. Agents Chemother. 2004, 48, 4566-4573. [CrossRef]

29. Leski, T.A.; Tomasz, A. Role of penicillin-binding protein 2 (PBP2) in the antibiotic susceptibility and cell wall cross-linking of Staphylococcus aureus: Evidence for the cooperative functioning of PBP2, PBP4, and PBP2A. J. Bacteriol. 2005, 187, 1815-1824 [CrossRef]

30. Choo, E.J.; Chambers, H.F. Treatment of Methicillin-Resistant Staphylococcus aureus Bacteremia. Infect. Chemother. 2016, 48, 267-273. [CrossRef]

31. Sakoulas, G.; Moise-Broder, P.A.; Schentag, J.; Forrest, A.; Moellering, R.C., Jr.; Eliopoulos, G.M. Relationship of MIC and bactericidal activity to efficacy of vancomycin for treatment of methicillin-resistant Staphylococcus aureus bacteremia. J. Clin. Microbiol. 2004, 42, 2398-2402. [CrossRef] [PubMed]

32. Song, K.H.; Kim, M.; Kim, C.J.; Cho, J.E.; Choi, Y.J.; Park, J.S.; Ahn, S.; Jang, H.C.; Park, K.H.; Jung, S.I.; et al. Impact of Vancomycin MIC on Treatment Outcomes in Invasive Staphylococcus aureus Infections. Antimicrob. Agents Chemother. 2017, 61. [CrossRef] [PubMed]

33. Lodise, T.P.; Graves, J.; Evans, A.; Graffunder, E.; Helmecke, M.; Lomaestro, B.M.; Stellrecht, K. Relationship between vancomycin MIC and failure among patients with methicillin-resistant Staphylococcus aureus bacteremia treated with vancomycin. Antimicrob. Agents Chemother. 2008, 52, 3315-3320. [CrossRef] [PubMed]

34. Yang, C.C.; Sy, C.L.; Huang, Y.C.; Shie, S.S.; Shu, J.C.; Hsieh, P.H.; Hsiao, C.H.; Chen, C.J. Risk factors of treatment failure and 30-day mortality in patients with bacteremia due to MRSA with reduced vancomycin susceptibility. Sci. Rep. 2018, 8, 7868. [CrossRef]

35. Choe, D.; Szubin, R.; Dahesh, S.; Cho, S.; Nizet, V.; Palsson, B.; Cho, B.K. Genome-scale analysis of Methicillin-resistant Staphylococcus aureus USA300 reveals a tradeoff between pathogenesis and drug resistance. Sci. Rep. 2018, 8, 2215. [CrossRef]

36. Hebrard, M.; Viala, J.P.; Meresse, S.; Barras, F.; Aussel, L. Redundant hydrogen peroxide scavengers contribute to Salmonella virulence and oxidative stress resistance. J. Bacteriol. 2009, 191, 4605-4614. [CrossRef]

37. Tacconelli, E.; De Angelis, G.; Cataldo, M.A.; Pozzi, E.; Cauda, R. Does antibiotic exposure increase the risk of methicillin-resistant Staphylococcus aureus (MRSA) isolation? A systematic review and meta-analysis. J. Antimicrob. Chemother. 2008, 61, 26-38. [CrossRef]

38. Chen, P.R.; Bae, T.; Williams, W.A.; Duguid, E.M.; Rice, P.A.; Schneewind, O.; He, C. An oxidation-sensing mechanism is used by the global regulator MgrA in Staphylococcus aureus. Nat. Chem. Biol. 2006, 2, 591-595. [CrossRef] [PubMed] 